\title{
USO DIDÁCTICO DEL CÓMIC EN UN AULA MULTICULTURAL Y MULTIRRELIGIOSA DE INGLÉS
}

\author{
Irene Muzás Calpe, Universtität Potsdam-Zacharias Frankel College \\ (Alemania)
}

Email: irene.m.calpe@gmail.com

\begin{abstract}
Diego Rascón Moreno, Universidad Complutense de Madrid
Email: drascon@ucm.es
\end{abstract}

\begin{abstract}
Resumen: El cómic de superhéroes es un medio narrativo visual a través del cual los jóvenes pueden expresar sus emociones, y narrar y resolver hechos cotidianos. La clase de Inglés puede convertirse en un punto de encuentro entre alumnos de procedencias diversas. Estudiantes de la última etapa educativa de Educación Secundaria Obligatoria diseñarán unos personajes que defiendan unos valores éticos a partir de una reflexión sobre la Declaración de los Derechos Humanos. Dicha actividad tiene como objetivo linguístico la consolidación de destrezas de comprensión y expresión escrita. Como objetivo interdisciplinar, pretende fomentar el diálogo intercultural e interreligioso.
\end{abstract}

Palabras clave: Cómic, interculturalidad, diálogo interreligioso, clase de Inglés, Educación Secundaria.

Título en inglés: The didactic exploitation of comics in a multicultural and multireligious classroom of English.

Abstract: Superheroes comic-books are a visual narrative medium through which young people can express their emotions, and tell and solve everyday life situations. The English class can become a meeting point for pupils from different backgrounds. Students in the last educational stage of Compulsory Secondary Education will design characters who defend ethical values derived from a reflection on the Universal Declaration of Human Rights. The main linguistic objective of this activity is the consolidation of written comprehension and production skills. Its interdisciplinary objective is to promote intercultural and interfaith dialogue.

Keywords: Comic-book, interculturality, interfaith dialogue, English class, Secondary Education.

\section{INTRODUCCIÓN}

Desde hace unos años y gracias a los intensos flujos migratorios, nuestras aulas cuentan con alumnos procedentes de una amplia variedad de países. La multiculturalidad en nuestras aulas 
es un hecho, como lo es en nuestra sociedad, lo que conlleva necesariamente un entendimiento a través del diálogo entre culturas, costumbres (a veces hasta opuestas entre), y lenguas diversas. Si trasladamos ese panorama a la comunidad educativa, nos encontramos con que alumnos de procedencias muy diversas y en edades muy diferentes deben aprender a pasar muchas horas juntos, convivir y crecer durante años compartiendo un mismo espacio, unos recursos y unas experiencias durante las etapas posiblemente más críticas de su crecimiento.

\subsection{Justificación}

En este sentido la clase de lengua inglesa en la etapa de secundaria resulta un marco idóneo para fomentar el entendimiento entre alumnos de diferentes procedencias, ya que pueden exponer sus costumbres, tradiciones y valores utilizando como vía de comunicación una lengua con la que habitualmente no se comunican entre sí en la escuela. Pero, para poder encontrar un marco de valores común entre las diferentes sensibilidades étnicas y religiosas en el aula es necesario que los alumnos hablen de ello, conozcan al otro y dialoguen, es decir, que interactúen entre sí. En este contexto el uso del cómic puede convertirse en una herramienta muy útil para gestionar la diversidad cultural y religiosa en la clase de Inglés.

Dentro del mundo del cómic el de superhéroes goza de una inmensa popularidad entre los jóvenes, probablemente gracias al cine y a las grandes superproducciones basadas en este producto. El cómic de superhéroes en concreto es un medio narrativo visual dirigido a una franja de edad comprendida entre los doce y veinte años especialmente, es decir, que comprende desde la temprana pre-adolescencia hasta la adolescencia tardía, y en muchos casos más allá de la misma. Se trata de un medio muy sencillo a través del cual como lectores pueden sentirse identificados con situaciones y emociones expresadas por los personajes. Como medio de expresión, los jóvenes tienen la oportunidad de verbalizar -y de forma icónica- sus emociones, anhelos, preocupaciones, contradicciones, e incluso narrar hechos cotidianos, entre otras actividades.

La realización de un cómic de superhéroes en el aula implica un trabajo cooperativo, en el cual deberán diseñar un superhéroe o superhéroes y, por supuesto, un supervillano. La construcción de dichos personajes implicará debatir sobre cuáles son los valores que debe un superhéroe defender y cuáles los que un supervillano ataca. Se trata de que a través de la construcción de sus propios personajes, los alumnos dialoguen sobre sus propios valores y los compartan con sus compañeros, para poder encontrar un vínculo en común en la diferencia.

Dicho proceso de construcción de personajes se repetirá en la construcción propia de la narrativa, donde, de nuevo a través del debate y del diálogo deberán poner en común qué historias se proponen contar, quiénes serán los héroes y los villanos, quienes las víctimas a las que salvar, qué situaciones de la vida cotidiana quieren representar, qué diferentes puntos de vista tienen sobre una misma situación, y un sinfín de opiniones que deberán concretar en la elaboración del guion.

\subsection{Objetivos}

El objetivo general de este proyecto es crear un cómic de superhéroes que se propongan defender unos valores éticos en común, basados en la Declaración Universal de los Derechos 
Humanos (Organización de las Naciones Unidas, 1948). Se trata de que los alumnos reflexionen y dialoguen sobre los valores que tienen en común, independientemente de las diferencias culturales y religiosas que puedan tener cada uno, es decir, de trabajar hacia una educación intercultural en un aula multicultural y multirreligiosa los valores que les unen en la diferencia. En cuanto a los objetivos específicos de la asignatura de Inglés, se centrarán en consolidar diversas destrezas lingüísticas relacionadas con el uso de los diferentes tiempos narrativos y los tiempos de presente. Para ello se pondrá especial énfasis en la expresión oral y escrita de los alumnos.

\section{MARCO TEÓRICO}

En este apartado abordaremos el marco conceptual de nuestra propuesta. Este consiste de dos partes claramente diferenciadas. En primer lugar, al tratarse de una propuesta destinada a un aula multicultural, definiremos qué implicaciones tiene la educación intercultural en un aula con pluralidad de culturas y religiones.

En segundo lugar, abordaremos la materia sobre la que se va a basar nuestra propuesta: el cómic. En este apartado justificaremos por qué creemos que puede tratarse de una herramienta pedagógica fundamental para la educación intercultural.

\subsection{Educación intercultural en un aula multicultural}

El término multiculturalidad fue acuñado en los años 60 en el marco de la lucha por los derechos civiles en Estados Unidos. El multiculturalismo reconocía una pluralidad de culturas y dicho reconocimiento se incorporó en el currículo escolar, especialmente a partir de las postulaciones de Banks, basándose en la convivencia en las aulas con la comunidad afroamericana en EE.UU. El término multiculturalidad respondía a la necesidad de reconocer la diversidad cultural en las aulas, pero se trataba de un término que simplemente abogaba por la mera convivencia de dichas culturas, una mera "yuxtaposición" de las mismas enfocada hacia el grupo en sí, dejando a un lado la heterogeneidad del individuo (Muñoz Sedano, 1997: 97).

El enfoque intercultural nació una década más tarde y aboga por establecer canales de comunicación y diálogo entre culturas partiendo de un enfoque basado en la simetría cultural, es decir en un canal de comunicación entre iguales que comparten e interactúan y no en el simple reconocimiento de la pluralidad de culturas (op.cit, 102). La educación intercultural trata de hallar un punto de encuentro entre comunidades de diferente procedencia cultural que conviven en un mismo espacio. No se trata de comprender y conocer los particularismos culturales de cada grupo, sino de dialogar y conocerse, de construir un marco común que considere la variedad cultural una oportunidad y no un problema a resolver.

Según Essomba (2002) los objetivos de la educación intercultural son tres y cada uno de ellos no puede entenderse sin el otro: la función transformadora, el control del proceso y la función prospectiva. La función transformadora es inherente es una oportunidad que empieza en las aulas, en tanto en cuanto estas son un reflejo de la sociedad y viceversa, y es de esperar que los procesos transformadores que puedan derivarse de las acciones llevadas a cabo en el aula tengan una cierta repercusión en el aula. Sin embargo, como bien nos advierte 
Essomba ello es imposible si no se cuenta con el marco legal y jurídico adecuado fuera de las mismas, es decir, si la sociedad carece del marco legislativo adecuado que garantice los derechos y los deberes de los ciudadanos en un marco democrático de convivencia.

Por otro lado, por más que se quiera tener un total y absoluto control sobre el proceso, cualquiera que se dedique a la enseñanza sabe que eso no es posible en el aula, por lo que es probable que durante el proceso educativo se obtengan resultados diversos e inesperados. Es decir, el objetivo de una educación intercultural puede ser el entendimiento y el diálogo entre una diversidad multicultural, pero puede que nos encontramos con resultados adversos a pesar de tener las mejores intenciones. Y, en tercer lugar, si la realidad es una construcción, se deben dar desde las aulas los pasos necesarios para tratar de construirla todos juntos, y esto ha darse de una manera justa y equitativa.

Estos tres objetivos de la educación intercultural no son más que las metas a las que aspira una sociedad que cuenta con una pluralidad de culturas que no solo deben aprender a convivir, sino a interactuar y a enriquecerse de la diversidad que unos y otros aportan. Los tres objetivos descritos por Essomba tienen su equivalente en el individuo y su comportamiento, y en un proyecto intercultural en la escuela, determina tres niveles de comportamiento de cada uno de los miembros de la comunidad educativa. Estas variables comprenden aquello que sabemos, lo que queremos y lo que hacemos, es decir, lo cognitivo, lo emocional-afectivo y lo conductual.

Por lo tanto, y siguiendo el razonamiento de Essomba, en un marco de educación intercultural, estas tres variables nos aportan información sobre lo que sabemos o no de otras culturas, sobre lo que queremos conseguir de nuestra interacción con ellas, y de cómo vamos a proceder a partir de dicha interacción, en tanto en cuanto como individuos y como sociedad. En resumen, se trata de que toda la comunidad educativa se implique en el conocimiento mutuo, en un proyecto en común transformador y en una serie de actuaciones que se propongan un cambio en el entorno, desde la unidad, entendida como individuo, hasta el colectivo compuesto por la comunidad educativa, proyectada en la sociedad en su conjunto.

Sin embargo estos factores se tornan más complejos al abordar no solo la pluralidad de culturas, sino la pluralidad de opciones religiosas en el aula. Se trata de un tema complicado y delicado, ya que en la mayoría de los casos, lo cultural y lo religioso resultan dos realidades inseparables, y en muchos otros casos, lo que es religioso para unos, para otros es cultural. Essomba (2008) propone que aunque todo aquello que haga referencia a la práctica religiosa debe quedar relegado al ámbito familiar, hay que introducir contenidos en el currículo de una manera actualizada y novedosa, para que todos los miembros de la comunidad educativa conozcan y puedan interactuar con la pluralidad de culturas y religiones que les rodea. De lo que se trata, en palabras de Essomba es de aceptar comportamientos culturales de base religiosa "que no supongan una pérdida de cuotas de igualdad social [...] ni de libertad en la diversidad" (112). Por lo tanto, es necesario que la comunidad educativa conozca y conviva con la pluralidad religiosa que la forme, aunque su práctica pertenezca al ámbito privado, y que en ningún caso estas supongan comportamientos que atenten contra los derechos democráticos que garanticen convivencia social. 


\subsection{El cómic}

\subsection{1. ¿Qué es un cómic?}

El profesor José Luis Rodríguez Diéguez (1998), Catedrático de Didáctica de la Universidad de Salamanca, propone en su colección sobre los Medios de Comunicación en la Enseñanza, un repaso de las diferentes definiciones del cómic. En general, a pesar de los detalles que las diferencian, estas abordan el cómic desde dos puntos de vista. Por un lado, unas se centran en la descripción de este, y, por otro lado, otros autores se inclinan por clasificarlo por su funcionalidad. Estos parecen ser los dos puntos de vista en los que coinciden la mayoría de teóricos que no se dedican al medio más que desde un punto de vista meramente especulativo.

Por ejemplo, Román Gubern es uno de los autores que optan por una definición en base a su forma aludiendo que básicamente se trata de "una estructura narrativa formada por la secuencia progresiva de pictogramas, en los cuales pueden integrarse elementos de escritura fonética" (citado en Rollán Méndez y Sastre Zarzuela, 1986: 19). Por otro lado, autores como Umberto Eco lo definen por su funcionalidad de entretenimiento y divertimento de masas, y su fijación de iconos y mitos en el imaginario colectivo (Rodríguez Diéguez, 1998). Sin embargo, más adelante en su estudio Rodríguez Diéguez admite que, si bien en un principio el único fin del cómic era el divertimento, como suponen la mayoría de estudiosos del tema, este acabó por adquirir, ya fuera por necesidades sociales, o por el prestigio social que ello supone, un carácter instructivo. Rodríguez Diéguez concluye así, que se trata de un medio de comunicación de masas con el que uno puede aprender divirtiéndose, y, por lo tanto tiene una serie de aplicaciones didácticas a tener en cuenta.

El renombrado autor de cómics y teórico del medio Will Eisner (2002) fue más allá de la consideración de la forma como tal y revolucionó el estudio del mismo al considerar la integración de palabra e imagen como un arte en sí mismo, redefiniendo el cómic como arte secuencial. Según Eisner es un medio de expresión en el que no solo se ha de saber leer las palabras del texto, sino de integrar palabra e imagen, de descifrar símbolos y de lograr aprender a leer otro tipo de lectura que no tenga como objetivo simplemente la palabra escrita. Se trataría de combinar las particularidades del dibujo y las de la literatura, creando una superposición entre ambas que se conjugaría en una gramática del cómic o arte secuencial. En definitiva, se trata de un arte interdisciplinario y, como tal, Eisner le atribuye dos funcionalidades, en primer lugar, la enseñanza, y en segundo lugar el entretenimiento.

Sin embargo, la aplicación didáctica a la que alude Eisner es más instrucción que enseñanza desde un punto de vista pedagógico, ya que se refiere a la utilización del cómic para ilustrar manuales y folletos, a lo que dedicó gran parte de su vida profesional. Eisner encarna el ejemplo de autor de cómics que ha conjurado las tres facetas de las que hemos hablado hasta ahora casi sin proponérselo, en primer lugar como autor de cómics de entretenimiento en el que el protagonista es un héroe enmascarado que persigue a criminales y malhechores: The Spirit. Después se dedicó a publicar folletos y manuales para el ejército americano, y más tarde inventó el cómic de arte y ensayo o novela gráfica, 
en la que utilizó el medio para publicar historias de contenido social y de denuncia, con un tono más realista y oscuro.

\subsubsection{Breve historia del cómic de superhéroes}

El origen del cómic como medio de comunicación de masas se originó a finales del siglo XIX en EEUU en las tiras de los diarios. Yellow Kid [El niño amarillo] fue el título del que se considera la primera tira de cómic y fue creado por Richard F. Outcault. En España el origen se remonta a las Aucas publicadas en Cataluña y Levante, que consistían en una disposición de dibujos enmarcados con una pequeña frase debajo que acompañaba la historia representada en las ilustraciones. Sin embargo, el primer cómic publicado en España fue En Patufet en 1904 en Cataluña y T.B.O en 1917 en el resto de España, este último dando nombre al cómic en España que pasó a denominarse "tebeo", hasta la irrupción en masa de los cómics de superhéroes durante la década de los ochenta del siglo pasado (Rollán Méndez y Sastre Zarzuela, 1986: 23).

El auténtico auge del cómic se vivió con la irrupción en los kioscos de EE.UU de los cómics de superhéroes. Con la aparición de Superman en 1938, creado por Jerry Siegel y Joe Shuster, y publicado por Detective Comics el cómic alcanzó cifras récord de ventas dos años después de su primera publicación con más de 1.400 .000 ejemplares vendidos (Gubern, 2002). Casi simultáneamente apareció Batman (1939), creado por Bob Kane y Bill Finger y publicado también por Detective Comics. Sin embargo, Batman no poseía poderes extraordinarios como el kryptoniano Superman, sus poderes y habilidades eran fruto de su férreo entrenamiento y de la voluntad de acabar con toda injusticia tras el asesinato de sus padres. Pero fue la figura del superhombre de capa roja la que cosechó más imitadores y así, los siguientes años vieron el nacimiento en viñetas de otros tantos seres con poderes sobrehumanos como el Capitán Marvel (1940), Wonder Woman (1941) o Supergirl (1958) (op cit, 286).

Durante la década de los cincuenta los cómics de superhéroes entraron en decadencia y sus ventas bajaron espectacularmente. Las razones no solo responden a un decreciente interés por parte de los lectores, sino también por la intervención de la censura en los cómics y del comité censurador que creía que los cómics resultaban perniciosos para las mentes de los más jóvenes y máximos consumidores del medio. Además, no solo los superhéroes sempiternos como Batman, o Superman habían perdido ventas espectaculares, sino que la franquicia rival de Detective Comics, la futura Marvel Comics, parecía incapaz de crear personajes que pudieran rivalizar con las viejas glorias del pasado reciente. Pero todo eso cambiaría con la llegada de los nuevos grupos de superhéroes.

Como explica el propio autor en el documental Superheroes: A Never-Ending Battle [Los superhéroes: una batalla interminable], dirigida por Michael Kantor en 2013, en 1961 un joven Stan Lee revitalizó el mundo del cómic de superhéroes con la creación de Los 4 Fantásticos. En ese momento, Detective Comics estaba empezando a triunfar con la recién creada Liga de la Justicia de América, una reunión de los principales superhéroes de la franquicia, quienes, en lugar de ser publicados en sus series regulares empezaron a publicarse juntos. Stan Lee y Jack Kirby aprovecharon la idea y crearon el primer grupo 
de superhéroes de la que más tarde se convertiría en la franquicia de cómics con mayor éxito del mundo, Marvel Comics.

Esta nueva formación supuso un aire fresco para el mercado y una sorpresa de ventas y éxito, que ni el propio Stan Lee se puede explicar, como confiesa en el documental mencionado. Sin embargo, Stan Lee apunta que, probablemente, parte del éxito de Los 4 Fantásticos pudo deberse al hecho de contactar con el público estadounidense que vivía en plena era atómica, y los peligros de la radiación. En el apogeo de la Guerra Fría, el público podía identificarse con un accidente radiactivo, pero ya no con la mitología transformada en superpoder. Algo de razón debía tener, cuando, al mismo tiempo, Detective Comics, relanzó una de sus viejas glorias, The Flash, dándole un nuevo origen basado en otro accidente de laboratorio, convirtiéndose en su mayor éxito de ventas en décadas. Al éxito de Los 4 Fantásticos le siguieron otros en 1963: Los Vengadores y los X-Men, conocidos en España como La Patrulla X.

\subsubsection{Los X-Men, el poder de la diferencia}

Los $X$-Men es un grupo de superhéroes formado por mutantes, es decir, son un grupo de adolescentes a los que, al cumplir los trece años, al inicio de la pubertad, se despierta su gen mutante y sufren una serie de cambios físicos producidos por el despertar de una serie de habilidades que desconocen, que no son capaces de controlar y manipular, que les asusta, y, que en ocasiones, cuando estos conllevan cambios físicos importantes, provocan el rechazo de quienes les rodean. Se trata, por así decirlo, de una fabulosa metáfora de la adolescencia.

Sin embargo, a lo largo de las décadas de publicación, este grupo de superhéroes ha encarnado algo más que la realidad adolescente de ser diferentes transformada en fantasía, al tener el consuelo de poseer un poder extraordinario. En 1975, de la mano de Len Wein y de Dave Cockrum hacen su aparición los nuevos $X$-Men con los que la editorial pretendía relanzar la colección. Y la fecha no es casual, ni la procedencia de los nuevos componentes del grupo es fruto meramente del capricho de sus autores. Esta vez no se trataba de cinco adolescentes caucásicos norteamericanos, sino de miembros de muy diversa procedencia, en ocasiones, en conflicto entre sí. Los miembros de esta segunda génesis del grupo lo conforman un canadiense, Lobezno, un alemán de pelaje azul, Kurt Wagner (Rondador Nocturno), una mujer africana, Ororo Munroe (Tormenta), un ciudadano de la Unión Soviética, Piotr N.Rasputin (Coloso), un japonés, Shiro Yoshida (Fuego Solar), y John Estrella Orgullosa (Ave de Trueno), nativo americano (Véase Anexo). Ciertamente el grupo de superhéroes multicultural por antonomasia.

Según Unai Velasco (2015) los X-Men encarnan la historia de la diferencia, sí, pero de la identidad de la diferencia, lo que engloba mucho más que la adolescencia, como quedó demostrado en 1975 con la publicación de Giant-Size X-Men \#1 y sus nuevos componentes, y en las décadas siguientes. ¿Si no se trataba de la adolescencia simplemente, cómo se trató la diferencia en esta colección? Según Velasco, en primer lugar, se trata de una diferencia que crea un conflicto psicológico, en el que el héroe debe ocultarse tras una máscara no solo por miedo a ser reconocido, sino como protección del mundo exterior, es más, la máscara es "símbolo doble de su miedo a lo real: miedo a que aquello que entendemos por realidad 
no nos acepte y nos rechace, y miedo incluso a no saber si uno mismo -la parte otra de uno mismo- es real" (p. 59).

Por otro lado, la identidad pasa a convertirse en conflicto sociológico cuando la diferencia se convierte en motivo de rechazo social, de exclusión y enfrentamiento. Como apunta Velasco, esto tiene una explicación desde el inicio mismo de la serie, y, en nuestra opinión en el origen mismo de los cómics y de sus autores. Tanto los creadores de Superman, Siegel y Shuster, como los de Batman, Kane y Finger, como los creadores de los X-Men, Stan Lee y Jack Kirby, procedían de familias judías que habían huido de los pogromos acontecidos en territorio ruso a mediados y finales del siglo XIX, y de la persecución sufrida por el auge del nacionalsocialismo en la Alemania de la década de los años treinta del siglo pasado. De hecho, gran parte de la plantilla de Detective Comics y de la que pasó a convertirse en Marvel Comics, procedía de familias judías y sabían perfectamente qué era sentirse diferente, y qué terribles consecuencias podía acarrear la intolerancia y el desprecio social.

El mismo guionista Chris Claremont, quien dio el empuje definitivo a los X-Men en las décadas de los ochenta y noventa, así como su mayor carga política e ideológica, es de origen judío y, como todo hijo de inmigrantes judíos de la época, sabía a qué terribles consecuencias podía enfrentarse aquel que fuera percibido como diferente. Por lo tanto, Velasco considera que no es descabellado que ese sentimiento de la diferencia y de la marginación impregnara las obras de autores como Lee y Kirby y que ese fuera precisamente uno de los motores narrativos de la serie.

Además, la identidad de la diferencia se traslada al lenguaje del cómic mismo, ya que, si en algo se diferenció la serie de las otras colecciones de superhéroes es que los lectores podían disfrutar tanto de sus aventuras luchando contra intrépidos villanos, como inmiscuirnos en su intimidad, en su día a día y ver cómo disfrutan de su "tiempo libre". Esto confería al lector una normalidad y una cercanía no antes vista en los cómics de superhéroes y que, a buen seguro, contribuyó al éxito de la serie. De este modo, el superhéroe no se presenta como la encarnación de una fantasía del diferente con poderes, y, por tanto, capaz de defenderse contra quienes le atacan, sino de un personaje con el que, más allá de su diferencia, el lector se puede identificar y reconocer.

\subsubsection{El cómic como medio pedagógico}

Como ya vimos anteriormente, el mismo Will Eisner (2002) señalaba la importancia del cómic como herramienta pedagógica para ilustrar las instrucciones de uso de diversos aparatos (141). Sin embargo, el cómic ha encontrado también su utilidad en las aulas. Al ser un medio de comunicación de masas que no precisa de ningún tipo de mediador técnico para su uso en el aula su utilización es de una gran simpleza y a la vez muy efectivo (Rodríguez Diéguez, 1998). Además, se trata de un medio que se encuentra al alcance de los jóvenes, y hoy en día gracias al cine su difusión es aún mayor. Al tratarse de un medio que, como hemos visto, combina literatura e imagen, los objetivos y los contenidos, así como sus posibilidades son múltiples.

Quedó claro en epígrafes anteriores, que el cómic es un medio de comunicación de masas con el que no solo se puede aprender, sino también divertirse, por lo que ya de por 
sí se trata de una herramienta pedagógica motivadora. Además, se trata de un método interdisciplinar ya que, como indican Rollán Méndez y Sastre Zarzuela (1986), el cómic no solo es un medio que suscita el interés de los alumnos sino que aglutina características específicas de otras disciplinas tales como el teatro (diálogos), la novela (narrativa), la pintura y el dibujo, el cine y la televisión (técnica narrativa) y la fotografía (12).

Al tratarse de un medio icónico, los objetivos a conseguir con el uso del cómic en el aula son múltiples y variados. Rodríguez Diéguez ya nos ofrecía varias alternativas en su estudio sobre la utilización didáctica del cómic (132) centradas en el uso del lenguaje verboicónico, es decir, de la combinación del lenguaje narrativo verbal y a través de imágenes, lo que Will Eisner denominó arte secuencial. Por tanto, según Rodríguez Diéguez, el hecho que los alumnos tengan que enfrentarse a la producción y reproducción de dicho medio expresivo que combina ambas formas narrativas favorece no solo la reflexión lingüística por parte del alumno, sino también su capacidad analítica. En las actividades propuestas también hace constar la consecución de una metodología que combine el trabajo cooperativo e individual tanto en la expresión como en la interpretación, y el fomento de la creatividad, como aspectos positivos a tener en cuenta. Sin embargo, en el aspecto que Rodríguez Diéguez incide con mayor vehemencia es en los contenidos actitudinales. El uso del cómic en las puede aportar a los estudiantes valores tales como la empatía y la tolerancia, ya que, favorece una actitud positiva ante la crítica, siempre y cuando el cómic de pie a una serie de coloquios o debates a discutir (132-133).

Así pues, el cómic en el aula se ha utilizado para trabajar no solo contenidos conceptuales y procedimentales de diversas disciplinas, sino también contenidos actitudinales. En su estudio sobre las aplicaciones didácticas del cómic en la escuela, Rollán Méndez y Sastre Zarzuela (1986) analizan un amplio abanico de las diferentes áreas en las que trabajar el cómic en la escuela, que van desde las áreas de expresión a las áreas de experiencia. Entre las áreas de expresión se hace especial hincapié en su aplicación a la lectura y la entonación, la escritura y rotulación, el uso del vocabulario, la ortografía, la dramatización o la redacción. Mientras que en las áreas de experiencia, dividen las aplicaciones que el cómic pueda tener entre el área de las Ciencias Naturales, y el área "Humana".

En esta última, los temas varían entre los "temas globalizados”, es decir, según los autores, los temas transversales que convergen en la consecución de varias materias, la historia, la geografía y la cuestión cívico-ética. Es esta última cuestión la que nos concierne y la que consideramos más relevante para la actividad que proponemos (208). Para las cuestiones cívico-éticas estos autores analizan la situación desde la perspectiva de España en la década de los ochenta, etapa previa a la explosión de la globalización y las tecnologías de la información y de la comunicación, pero a nuestro modo de ver, los contenidos conceptuales, procedimentales y actitudinales que describen bien pueden sernos de utilidad hoy en día.

Rollán Méndez y Sastre Zarzuela consideran el cómic como una herramienta interesante para activar unos objetivos fundamentales tales como "hábitos de comportamiento libre y responsable; actitudes favorecedoras de la convivencia; virtudes éticas y comunitarias" (208). Efectivamente, a través del comportamiento de los personajes, y del consecuente castigo o premio que reciba su comportamiento, los alumnos verán reflejado un comportamiento a seguir, o no. Rollán Méndez y Sastre Zarzuela proponen una serie de acciones para lograr tal objetivo que básicamente consiste en el diseño de unos personajes que se distingan por 
sus virtudes éticas y cívicas, y el diseño de unos "antihéroes" cuya comportamiento sea la antítesis de los primeros; la inclusión de personajes de la vida real interactuando con dichos personajes; la plasmación de situaciones y de temas cívicos, éticos y sociales a discutir (209).

La estructura para trabajar contenidos ético-cívicos no varía en otros autores como ya el antes mencionado Rodríguez Diéguez en su estudio sobre el cómic y su utilización didáctica, aunque este se centra en contenidos conceptuales y procedimentales dedicados al análisis lingüístico e icónico. En el estudio de Rodríguez Diéguez, al contrario que Rollán Méndez y Sastre Zarzuela, los contenidos actitudinales cobran una importancia relativa y se pone el énfasis en la estructura del cómic en sí y en las posibilidades narrativas, tanto de expresión, como de análisis que el medio pueda suscitar.

\section{PROPUESTA DE INTERVENCIÓN: UN CÓMIC DE SUPERHÉROES EN UN AULA MULTICULTURAL}

En un aula multicultural la propuesta de la elaboración de un cómic supone un desafío mayor, y no por ello menos apasionante. Ante una pluralidad de culturas y de religiones, la lengua inglesa actúa como vehículo neutro de expresión en el aula, es decir, los alumnos deben comunicarse en una lengua que no es propia de ninguno de los alumnos en clase, y por tanto, se convierte en lengua de cohesión, ya que están todos en igualdad de condiciones. Cabe destacar que esta propuesta de intervención se llevará a cabo de modo transversal entre la clase de Inglés y la de Arte, por lo que resulta necesaria la colaboración de ambos profesores para poder llevar a cabo la actividad.

\subsection{Objetivos e hipótesis}

En referencia a la clase de Inglés, se pretende el uso de los tiempos verbales en su conjunto, por tanto se contempla como una actividad final, de tercera evaluación. Así pues, uno de los objetivos es usar adecuadamente los tiempos narrativos (Pasado Simple, Pasado Continuo, Pasado Perfecto) y los tiempos de presente (Presente Simple, Presente Continuo y Presente Perfecto), y saber diferenciar el uso de unos y otros en contextos y/o situaciones reales representadas en las viñetas. Además, con este proyecto se intentarán mejorar las destrezas relativas a la expresión oral y escrita de los alumnos.

Los objetivos en lo que concierne a la gestión de una aula multicultural propiamente consisten en lograr un acuerdo y entendimiento entre los diferentes puntos de vista de las diferentes culturas y religiones que conviven en el aula. Queremos aclarar que con el término religión no solo se tiene en cuenta la religión o credo religioso del alumno, o del contexto familiar del alumno, sino también la ausencia del mismo. Es decir, tanto se tendrá en cuenta la cultura religiosa de unos, como la ausencia de la misma, ya que ambas presuponen una serie de valores a tener en cuenta que fácilmente pueden entrar en contradicción y/o conflicto, especialmente en franjas de edad como a la que está destinada esta propuesta.

Mediante la creación de un cómic de superhéroes, la clase deberá llegar a un entendimiento desde la diversidad cultural y religiosa. Al preparar el guion y la concepción de los personajes, los alumnos se verán obligados a dialogar y debatir sobre los valores que dichos superhéroes van a encarnar. Para ello, deberán tratar de encontrar los puntos 
en común que los personajes vayan a representar y defender. No solo deben ponerse de acuerdo en los valores de cada personaje, sino que deben definirlo físicamente. Al tratarse de la gestión de un aula multicultural, creemos que deben construir no solo un superhéroe, sino un grupo de superhéroes que luchen por una causa común, pero cada uno desde su diferencia, con sus contradicciones y las múltiples preguntas que puedan surgir entre ellos.

\subsection{Contenidos}

Los contenidos de esta propuesta serán de cuatro tipos: conceptuales, procedimentales, actitudinales y transversales. Los contenidos conceptuales a tener en cuenta serán los tiempos narrativos (Pasado Simple, Pasado Continuo y Pasado Perfecto) y los tiempos de presente (Presente Simple, Presente Continuo y Presente Perfecto). Los contenidos procedimentales a tener en cuenta serán la expresión oral y escrita del uso de los tiempos narrativos y de presente, el trabajo en grupo, y la tormenta de ideas. Los contenidos actitudinales a tener en cuenta serán la disposición del trabajo grupal, la implicación en el aprendizaje, la tolerancia y la empatía. Los contenidos transversales irán de acuerdo con el Proyecto Educativo de Centro (PEC) y en colaboración con otras asignaturas como Educación Plástica y Visual.

\subsection{Metodología}

La metodología a emplear será comunicativa y participativa y combinará el trabajo cooperativo e individual. A través del trabajo cooperativo los alumnos debatirán sobre los puntos clave para la creación de los personajes y el guion. Es importante crear grupos en el aula que combinen alumnos que provengan de diferentes culturas, ya que se busca enriquecer el discurso con el diálogo y la interacción entre miembros de diferentes realidades culturales y/o religiosas.

Para lograr un diálogo y una interacción fluida, pretendemos que en primer lugar se haga una reflexión individual sobre qué valores tienen en común, por lo que se ofrecerá un análisis individual de la Carta de los Derechos Humanos, que podrán utilizar como punto de partida de discusión. Además, con el trabajo individual, se pretende desarrollar una actitud crítica hacia el trabajo de los compañeros y de ellos mismos, para que aprendan a trabajar no solo el sentido crítico, sino también valores de tolerancia, respeto y empatía hacia el trabajo de los otros.

Además se utilizarán medios audiovisuales como películas y fragmentos de documentales extraídos de YouTube. Como hemos mencionado en epígrafes anteriores, los cómics de superhéroes han adquirido gran popularidad durante la última década al haber sido llevadas a la gran pantalla algunos de los arcos argumentales de más éxito. En el caso de los X-Men, que utilizaremos como modelo para la creación del grupo de superhéroes, han sido cinco las adaptaciones llevadas al cine. Las películas se visualizarán en versión original subtitulada y vendrán acompañadas de unos dosieres a trabajar por grupos en el que deberán responder a una serie de preguntas sobre el comportamiento ético de los personajes y la narración. La visualización de la película es una excelente herramienta para ver a los personajes en acción y aprender vocabulario básico para la consecución de la propuesta. 
En este caso la película propuesta es X-Men: Primera Generación [X-Men: First Class], debido al contenido ético en el que se debaten los protagonistas de la película y el dilema moral sobre la convivencia que propone al final. Creemos que puede resultar un punto de partida interesante para iniciar un debate sobre la tolerancia de minorías y de la diferencia. En cuanto a los fragmentos de documentales se visualizarán comentarios de autores de cómics, en el que explicarán los orígenes de algunos de los superhéroes más emblemáticos, y de cómo se les ocurrió a sus creadores.

\subsection{Destinatarios}

Esta propuesta está dirigida a alumnos de $3^{\circ}$ y $4^{\circ}$ de la Educación Secundaria Obligatoria (ESO). Consideramos que es la etapa educativa idónea para debatir en profundidad los temas éticos sobre convivencia y multiculturalidad que pueden surgir entre compañeros. Además, se tratarán de consolidar las destrezas básicas lingüísticas que se hayan abordado a lo largo de la ESO, especialmente en lo que se refiere a comprensión y expresión escrita. Se tendrá en cuenta lo que dispone la LOMCE (Ley Orgánica 8/2013) y la legislación autonómica (Decreto 51/2012), y en caso necesario se aplicarán las necesidades especiales que puedan ser precisas para el desarrollo de la misma en el contexto de enseñanza-aprendizaje concreto.

\subsection{Cronograma}

A continuación presentamos una propuesta del cronograma de actividades y su temporalización para esta unidad didáctica pensada para ser llevada a cabo durante dos semanas de clase, en seis sesiones de la clase de Inglés (véase la tabla 1). Al tratarse de una unidad didáctica transversal, la realización del cómic se llevaría a cabo en la clase de Educación Plástica y Visual partiendo del diseño de personajes y del guion elaborado en la clase de lengua extranjera.

\begin{tabular}{|l|c|c|}
\hline \multicolumn{1}{|c|}{ Actividad } & $\begin{array}{c}\text { Tipo de } \\
\text { agrupación }\end{array}$ & Temporalización \\
\hline $\begin{array}{l}\text { Trabajo cooperativo de comprensión y } \\
\text { expresión escrita en la que cada alumno lee } \\
\text { y reflexiona sobre uno o dos artículos de } \\
\text { la Declaración Universal de los Derechos } \\
\text { Humanos a escoger. }\end{array}$ & Individual & 20 minutos \\
\hline $\begin{array}{l}\text { Trabajo cooperativo de comprensión y } \\
\text { expresión oral en el que comentan por qué han } \\
\text { escogido esos artículos }\end{array}$ & Grupal & 10 minutos \\
\hline
\end{tabular}




\begin{tabular}{|l|c|c|}
\hline $\begin{array}{l}\text { Trabajo cooperativo en el que responderán a } \\
\text { unas preguntas de comprensión oral sobre la } \\
\text { película X-Men: Primera Generación }\end{array}$ & Por parejas & $\begin{array}{c}132 \text { minutos } \\
\text { (película) } \\
25 \text { minutos } \\
\text { (dossier) }\end{array}$ \\
\hline $\begin{array}{l}\text { Realizar un ejercicio de comprensión oral en } \\
\text { el que visualizan fragmentos de un documental } \\
\text { sobre cómo crear superhéroes }\end{array}$ & Grupal & 20 minutos \\
\hline $\begin{array}{l}\text { Trabajo cooperativo de expresión escrita en } \\
\text { el que diseñan y describen un superhéroe por } \\
\text { grupos de 3-4 alumnos }\end{array}$ & Grupal & 40 minutos \\
\hline $\begin{array}{l}\text { Exposición oral en el que presentan los diseños } \\
\text { de superhéroes al resto de la clase }\end{array}$ & Grupal & $\begin{array}{c}\text { presentación } \\
\text { prunutos por }\end{array}$ \\
\hline $\begin{array}{l}\text { Trabajo cooperativo en el que diseñan un guion } \\
\text { para tres páginas basado en la intervención de } \\
\text { uno de los superhéroes en una situación real. }\end{array}$ & Grupal & 55 minutos \\
\hline
\end{tabular}

Tabla 1. Cronograma de actividades y temporalización.

\subsection{Recursos}

Los recursos pueden dividirse en tres tipos: humanos, materiales y espaciales. Los recursos humanos son los profesores y alumnos. Los materiales que se utilizarán serán lápices, bolígrafo, fotocopias, material audiovisual (DVD), papel, ordenador, proyector y pantalla. El espacio donde se desarrollará será el aula de la clase de Inglés, el aula de la clase de Arte y el aula audiovisual.

\subsection{Forma de evaluación prevista}

En la evaluación prevista se evaluará tanto la acción formativa, como a los alumnos. En la evaluación formativa se comprobarán, entre otros aspectos, si los objetivos propuestos se han cumplido, si los contenidos han sido adecuados y si la temporalización ha sido correcta. En cuanto a la evaluación de los alumnos, se incluye la observación y las propias actividades del tema.

\subsection{Resultados previstos}

El objetivo primordial de esta propuesta es lograr un mayor entendimiento entre alumnos de diversa procedencia cultural y/o religiosa, y estimamos que el hecho de poder hablar libremente de quién es cada uno y qué es importante para cada uno a través de una lengua 
que no es la propia favorecerá dicha comunicación. El hecho de verse obligados a trabajar cooperativamente en grupos heterogéneos y crear un producto con cierta libertad donde puedan explicarse y expresarse, les permitirá conocerse mejor unos a otros, no solo como representantes de una cultura concreta, sino como individuos procedentes de otro contexto cultural diferente al propio.

Al tratarse de una actividad de final de curso, en la que los alumnos podrán poner en práctica objetivos lingüísticos trabajados a lo largo del curso, servirá como apoyo para una revisión final de la materia. Esperamos lograr cultivar un mayor interés por el otro en el aula, y despertar cierta curiosidad por un medio de comunicación de masas como el cómic, que permite poner en práctica destrezas lingüísticas como la expresión y comprensión escrita.

\section{DISCUSIÓN}

La propuesta que hemos presentado pretende ser una contribución más a la implantación de una educación intercultural en nuestras aulas. A través de un medio de comunicación que goza de bastante popularidad entre los jóvenes, pretendemos utilizarlo como excusa para fomentar una educación en valores, fundamentada en el entendimiento entre las culturas y religiones diversas que cada vez más pueblan nuestras aulas.

La propuesta consiste en ofrecer a los alumnos la posibilidad de conocerse mejor, no solo como colectividad, sino como individuos procedentes de un marco cultural en concreto, y lograr que, a través de la creación de unos personajes y de un guion de cómic, creen unos superhéroes que encarnen unos ideales en común. Para poder llevar a cabo este proyecto, resulta necesario que colaboren al menos dos departamentos, el Departamento de Idiomas y el Departamento de Educación Plástica y Visual, ya que el cómic, como hemos podido constatar, es un medio de comunicación verboicónico que combina literatura e imágenes para explicar una historia.

Cuando elaboramos esta propuesta, teníamos en mente un aula multicultural como en las que hemos tenido oportunidad de impartir clase, en la que había presencia de alumnos de procedencias muy diversas, como Marruecos, Bangladesh, China o Filipinas. Pero la diferencia no solo hacía referencia a la diversidad geográfica de las familias de los chicos, sino también a la diferencia religiosa. Así, hemos tenido grupos de clase formados por católicos, evangelistas, hindúes, laicos, judíos, musulmanes y ateos militantes. A lo largo de la investigación casi todos los ejemplos prácticos que hemos encontrado al tratar la multiculturalidad en las aulas hacían referencia al uso del pañuelo de las niñas musulmanas, o al absentismo escolar por parte de miembros del colectivo del pueblo gitano.

Evidentemente se trata de los ejemplos que más destacan porque son los que han despertado mayor atención mediática, y porque son los más visibles. Sin embargo, creemos que hace falta un mayor debate sobre la visibilización de otros colectivos religiosos en el aula. Si queremos avanzar hacia una educación intercultural, debemos optimizar la información y los recursos en el currículo escolar sobre dichos grupos. Si bien es cierto que España es un estado cuyas costumbres están fuertemente arraigadas en el catolicismo, muchas de ellas, como apunta Essomba (2008), han perdido su carácter religioso para convertirse en una actividad más de nuestro calendario de costumbres y tradiciones. Por ejemplo, gran parte de los ejercicios propuestos en los libros de texto de lengua inglesa, o en las páginas 
de recursos lingüísticos en la red, hacen referencia a la Navidad al llegar diciembre, o a Halloween al llegar octubre. Pocas hacen referencia a festivales como Diwali, Jánuca o el Ramadán, por citar algunos.

Sin embargo, ¿debemos renunciar a hacer actividades sobre la Navidad en el aula para no ofender a algunos o a casi todos los alumnos? No creemos que se trate de ofender, ni tan siquiera creemos que se deba obviar una tradición del país, pero sí que es necesaria una puesta al día de otras costumbres que están arraigándose en nuestro país, y que de ningún modo debemos entender como ajenas a nosotros, sino como parte de nuestra riqueza cultural cambiante. Essomba (2002) nos recordaba que para construir una sociedad intercultural es necesario construir una escuela intercultural en la que toda la comunidad educativa se implique. Estamos profundamente de acuerdo con este concepto. Es necesario tender puentes y dialogar a través de la escuela y de la educación, ya que la educación intercultural prioriza la valoración del otro, de la otredad, no con desprecio, sino con tolerancia y solidaridad.

Uno de los ejemplos más interesantes de educación intercultural como modelo para proyectar una sociedad intercultural, basada en los valores democráticos de respeto a la igualdad y a la solidaridad, es el proyecto Hand in Hand, Center for Jewish-Arab Education in Israel [De la mano, centro para la educación árabe-judía en Israel]. Se trata de una escuela que cuenta con más de 1.100 alumnos y con una comunidad educativa formada por más de 3.000 miembros por el momento, cuya misión consiste en construir una escuela y una comunidad cohesionada y bilingüe, donde la comunidad judía y árabe (ya sea cristiana, musulmana o laica) convivan poniendo el énfasis en los valores que les unen en democracia, no en los que les separan.

Contrariamente a lo que se podría esperar, para conseguir esto Hand in Hand no obvia la cuestión religiosa en su currículo escolar, sino que la aborda abiertamente y la visibiliza. Así, además de las asignaturas obligatorias que propone el Ministerio de Educación del Gobierno de Israel, Hand in Hand incluye en su currículo el bilingüismo (árabe y hebreo), la enseñanza de cristianismo, judaísmo e Islam, Educación por la Sociedad Civil y el conocimiento y respeto por otras culturas. En su Proyecto Educativo, concretan que solo abordando estos temas los alumnos podrán entender mejor una sociedad tan compleja y multicultural como la israelí.

\section{CONCLUSIONES}

Al realizar esta propuesta hemos tenido una serie de limitaciones que esperamos subsanar en el futuro. Una de las principales ha sido el no poder hacer un estudio de campo, es decir, el no haber puesto en práctica la propuesta, y ello ha derivado en una serie de impedimentos. En primer lugar, si hubiéramos podido ponerla en práctica, podríamos haber realizado un estudio sobre la aplicación de la teoría de las inteligencias múltiples de Gardner en la realización de un cómic. Al tratarse de una actividad interdisciplinar, habría resultado muy útil comprobar dicha teoría en la distribución de tareas.

En segundo lugar, si hubiéramos realizado el estudio de caso, habríamos podido constatar el grado de implicación del Departamento de Educación Plástica y Visual. No sabemos hasta qué punto los profesores de dicho departamento hubieran querido o podido colaborar con el proyecto por cuestiones de temporalización. Por otro lado, al no haber 
podido llevarlo a cabo con dicho Departamento, tampoco nos ha sido posible contrastar nuestro cronograma de actividades con el cronograma del Departamento de Educación Plástica y Visual.

En tercer lugar, no hemos podido evaluar la predisposición de los alumnos a comentar abiertamente costumbres o tradiciones. Es posible que algunos se nieguen a querer desvelarlo por miedo a represalias o a burlas. Para evitarlo será necesaria una preparación exhaustiva por parte del profesor o profesora y un plan de contingencia para prevenir casos en los que el alumno pueda sentirse ofendido. No hay que olvidar que los temas religiosos son de una gran complejidad y que pueden dar rienda suelta a estereotipos desafortunados y desencadenar conflictos no deseados en el aula.

Otra de las delimitaciones a tener en cuenta es de tipo curricular. La propuesta está pensada para llevarse a cabo en los dos últimos cursos de la ESO, pero mientras que en $3^{\circ}$ Educación Plástica y Visual es obligatoria, en $4^{\circ}$ es optativa. En el caso de $4^{\circ}$ ESO, tan solo llevarían a cabo el proyecto al completo los alumnos que cursaran dicha asignatura opcional, por lo que perdería parte de la riqueza interdisciplinar de la actividad.

El proyecto de crear un cómic de superhéroes podría ser un proyecto que implicara a todos los cursos de la Educación Secundaria Obligatoria. En este caso, podría tratarse no solo de un proyecto a realizar por el Departamento de Idiomas y el Departamento de Educación Plástica y Visual, sino un proyecto en conjunto desde dichos departamentos. Para poder implicar al resto de cursos, las tareas se podrían dividir de la siguiente manera: los grupos de $1^{\circ}$ y $2^{\circ}$ podrían colorear los dibujos que los de $3^{\circ}$ y $4^{\circ}$ hubieran diseñado, y los de $4^{\circ}$ podrían encargarse del guion partiendo de los superhéroes que los de $3^{\circ}$ hubieran inventado. Se trataría de implicar transversalmente a todos los cursos coordinados por los departamentos implicados.

En este caso se trataría de un proyecto más ambicioso, que implicaría toda una etapa educativa y en el que se podría realizar un estudio de campo de cómo responden los alumnos de $1^{\circ}$ y $2^{\circ}$ a la narración propuesta por los alumnos de $4^{\circ}$ y a los superhéroes diseñados por los de $3^{\circ}$. Los alumnos de la primera etapa educativa de ESO tendrían ocasión de poner en práctica sus destrezas lingüísticas de comprensión escrita al leer los textos enviados por alumnos de $4^{\circ}$ y las directrices de los alumnos de $3^{\circ}$ sobre cómo pintar a los diferentes personajes. Esta propuesta podría realizarse cada año y convertirlo en un rasgo distintivo de la escuela.

Durante esta propuesta hemos señalado que uno de los objetivos lingüísticos es la mejora de la expresión y comprensión escrita. Dichas destrezas podrían ampliarse a mejorar la expresión y comprensión oral si el cómic traspasa el papel y se convierte en una obra de teatro, donde los alumnos adaptan el guion y lo representan. En tal caso, no solo podría dramatizarse sino grabarse y crear un cortometraje, haciendo uso de las TIC. El corto podría grabarse con dispositivos móviles e incluso crear efectos especiales. Este sería un proyecto llevado a cabo junto con el Departamento de Tecnología.

En cualquier caso de lo que se trata es de implicar a la comunidad educativa en un proyecto en común que permita tender puentes de diálogo entre diferentes costumbres, culturas y tradiciones. Si la escuela puede proyectar la sociedad futura, es necesario abordar proyectos que permitan a los alumnos expresar su otredad para construir juntos una sociedad rica en la diferencia. 


\section{REFERENCIAS}

Decreto 51/2012, de 22 de mayo del Departament d'Ensenyament. Diari Oficial de la Generalitat de Catalunya, 6135, de 24 de mayo de 2012.

Donner, L. S., Goodman, G, Kinberg, S, Singer, B. (productores) y VAughn, M. (director) 2011. X-Men: Primera Generación. Estados Unidos / Reino Unido: Twentieth Century Fox.

EISNER, W. 2002. El cómic y el arte secuencial. Barcelona: Norma Editorial.

Essomba, M. A. 2002. Los objetivos de la educación intercultural. Aspectos diferenciales de su función y naturaleza. Coord. M. A. Essomba ( $2^{\mathrm{a}} \mathrm{Ed}$.), Construir la escuela intercultural. Reflexiones y propuestas para trabajar la diversidad étnica y cultural. Barcelona: Editorial Graó, de IRIF, S.L. 11-14.

----. (2008). 10 ideas clave. La gestión de la diversidad cultural en la escuela. Barcelona: Editorial Graó, de IRIF, S.L.

Gubern, R. 2002. Máscaras de la ficción. Barcelona: Editorial Anagrama. Hand in Hand (s.f.). Hand in Hand. Center for Jewish-Arab Education in Israel. Recuperado el 5 de julio de 2015 de https://www.handinhandk12.org

KAnTOR, M. (director) 2013. Superheroes: A Never-Ending Battle. [Video] YouTube.

Ley Orgánica 8/2013, de 9 de diciembre de Educación. Boletín Oficial del Estado, 295, de 10 de diciembre de 2013.

Muñoz Sedano, A. 2000. "Hacia una educación intercultural: enfoques y modelos." Encuentros sobre educación 1: 82-106.

Organización de las Naciones Unidas 1948. Declaración Universal de los Derechos Humanos. Recuperada el 4 de julio de 2015 de http://www.un.org/en/documents/udhr

Rodríguez Diéguez, J. L. 1998. El cómic y su utilización didáctica. Los tebeos en la enseñanza. Barcelona: Editorial Gustavo Gili, S.A.

Rollán Méndez, M.y Sastre Zarzuela, E. 1986. El cómic en la escuela. Aplicaciones didácticas. Valladolid: Instituto de Ciencias de la Educación, Universidad de Valladolid.

Velasco, U. 2015. Hombres en la encrucijada. Eds. E. Cucurella y A.S. Pareja (1 ${ }^{\text {a }}$ Ed.), Hijos del átomo. Once visiones de la Patrulla-X. Barcelona: Alpha Decay. 55-64. 


\section{ANEXO}



